Document downloaded from:

http://hdl.handle.net/10251/168875

This paper must be cited as:

Guardiola, C.; Pla Moreno, B.; Bares-Moreno, P.; Mora, J. (2020). Model-Based Ammonia Slip Observation for SCR Control and Diagnosis. IEEE/ASME Transactions on Mechatronics. 25(3):1346-1353. https://doi.org/10.1109/TMECH.2020.2974341

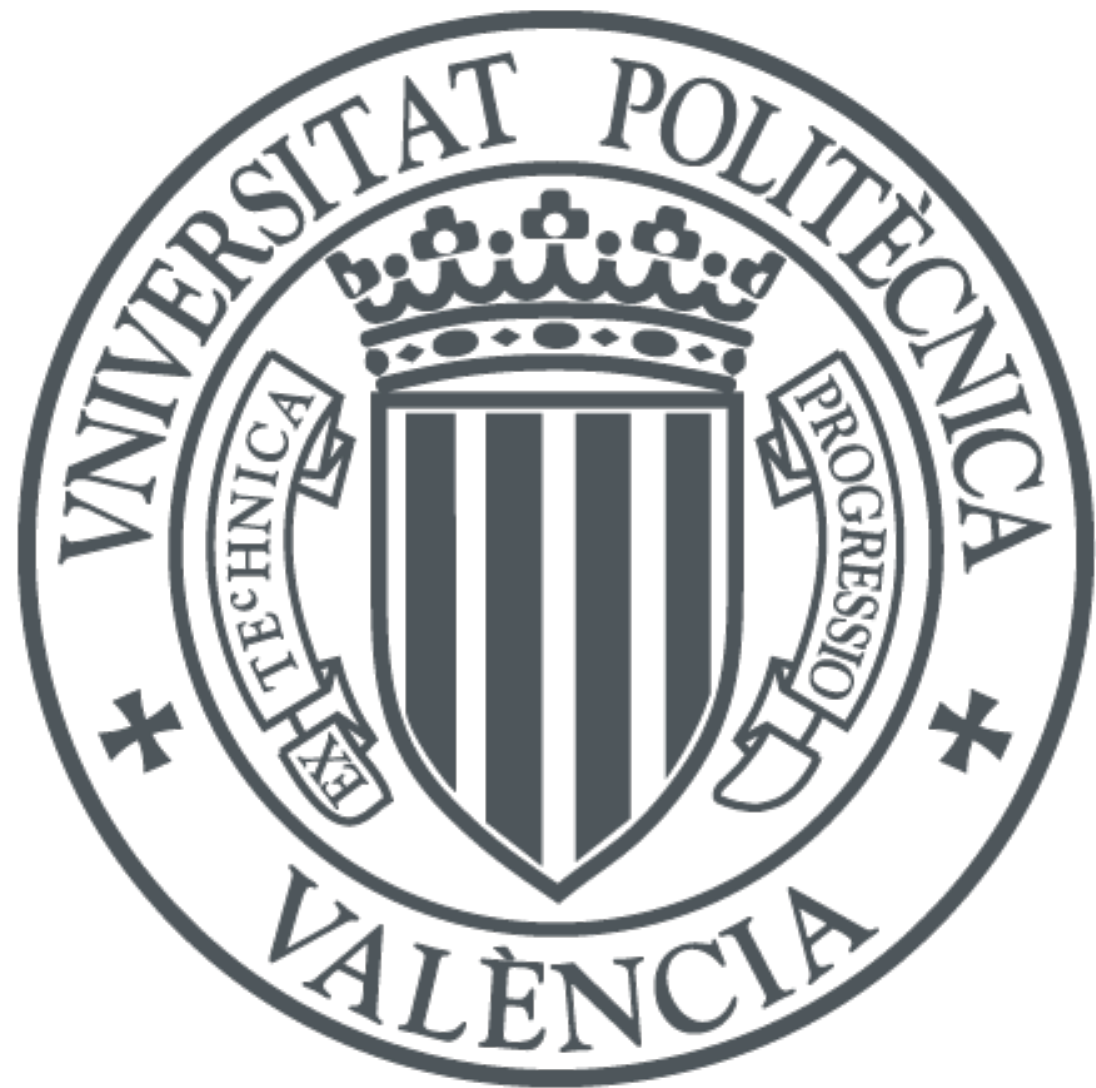

The final publication is available at

https://doi.org/10.1109/TMECH.2020.2974341

Copyright Institute of Electrical and Electronics Engineers

Additional Information

(C) 2020 IEEE. Personal use of this material is permitted. Permission from IEEE must be obtained for all other uses, in any current or future media, including reprinting/republishing this material for advertising or promotional purposes, creating new collective works, for resale or redistribution to servers or lists, or reuse of any copyrighted component of this work in other works. 


\title{
Model-based ammonia slip observation for SCR control and diagnosis
}

\author{
Carlos Guardiola, Benjamín Pla, Pau Bares, and Javier Mora,
}

\begin{abstract}
The control and diagnosis of selective catalytic reduction (SCR) system require from a precise estimation of NOx reduction in order to properly control the $\mathrm{NH}_{3}$ injection. This paper aims to resolve the cross-sensitivity of current NOx sensors at the outlet of the SCR, by providing the control unit with an estimation of NOx and ammonia slip.
\end{abstract}

The problem of discerning between NOx and ammonia slip is solved by identifying an intermediate variable representing the SCR load. The SCR load is estimated by combining the mass conservation principle between the inlet and the outlet of the SCR and a NOx reduction model, via an Extended Kalman filter. Current models and observers have several limitations to represent the real behaviour of the SCR along all the operating conditions: on one hand, when relying on the mass conservation, small errors at models are integrated, leading to important bias on the SCR load, on the other hand, the dynamics at the SCR difficult the observation and the adaptation of the model. The main focus of the developed algorithm is to use a simplified model which might be used for ammonia slip estimation, being aware of current limitations of SCR models in real operation.

Experimental results in a EURO 6 compression ignited (CI) engine show the potential of such observation in transient conditions and an adequate correlation with external ammonia measurements provided by additional sensors available on the test bench.

Index Terms-Diesel engine emissions, SCR, NOx sensor, crosssensitivity, Kalman filter

\section{INTRODUCTION}

Regulation requirements are evolving to meet society needs for a low polluted atmosphere [1]. For this purpose, new regulation procedures use portable emissions measurement systems (PEMS) in real driving emissions (RDE) conditions for type-approval procedures[1]. In this line, diesel after-treatment systems (ATS) have evolved to reduce pollutant emissions below regulation thresholds [2]. Specifically, selective catalytic reduction (SCR) systems allow reducing engine-raw $\mathrm{NO}_{\mathrm{x}}$ emissions, with the injection of ammonia $\left(\mathrm{NH}_{3}\right)$ in the exhaust line. However, due to the own SCR operation characteristics, $\mathrm{NO}_{x}$ and $\mathrm{NH}_{3}$ species may slip from the catalyst [3], [4]. Then, measuring these species slip on-board is relevant to keep emissions below the admitted threshold.

On-board sensors are required for control and on-board diagnostics (OBD), as it is the case of the SCR downstream $\mathrm{NO}_{\mathrm{x}}$ sensor [5], [6], [7], [8]. Specifically, this sensor is, for closed-loop control of $\mathrm{deNO}_{\mathrm{x}}$ systems, required to meet Euro

C. Guardiola, B. Pla, P. Bares and J. Mora work at Universitat Politècnica de València, 46022 Spain (corresponding author e-mail: pabamo@mot.upv.es).
6 emission targets [9]. However, it presents cross-correlation with $\mathrm{NH}_{3}$ [10], [11]. Therefore, $\mathrm{NO}_{\mathrm{x}}$ and $\mathrm{NH}_{3}$ signals must be decoupled from the sensor measurement, or it could lead, for instance, to instabilities in closed-loop control, if $\mathrm{NH}_{3}$ slip is considered as $\mathrm{NO}_{\mathrm{x}}$ slip. $\mathrm{A} \mathrm{NH}_{3}$ sensor could allow the $\mathrm{NO}_{\mathrm{x}}$ signal reconstruction [12], [13], [14], although depending on the vehicle segment, the inclusion of the $\mathrm{NH}_{3}$ sensor may be expensive [15]. Then, the aim of this article is to isolate both $\mathrm{NO}_{\mathrm{x}}$ and $\mathrm{NH}_{3}$ signals from the $\mathrm{NO}_{\mathrm{x}}$ sensor measurement, without the use of an on-board $\mathrm{NH}_{3}$ sensor measurement and by means of a Kalman filter.

Several configurations can be found in an after-treatment system with regards to blocks and sensors [16], [17], [18], [19]. In this sense, a diesel oxidation catalyst (DOC) or passive $\mathrm{NO}_{\mathrm{x}}$ adsorber (PNA) are usually placed in front of the exhaust line, while diesel particulate filters (DPF) and $\mathrm{deNO}_{\mathrm{x}}$ reduction systems can be found in [20]. In case an SCR is present, as it is the case of this work, an injector is placed upstream the SCR to inject an $\mathrm{NH}_{3}$-based solution [21], [22]. Then, for the purpose of this article, both SCR upand downstream $\mathrm{NO}_{\mathrm{x}}$ signals are considered available, while the downstream $\mathrm{NH}_{3}$ signal will be used to provide the $\mathrm{NH}_{3}$ slip, only for the algorithm calibration and validation.

Some works can be found in literature concerning SCR model approaches, from detailed 1D models to control-oriented OD models [23], [24], [25], [26], [27]. These models capture the different dynamics present in an SCR [28], [25]. While $\mathrm{NO}_{\mathrm{x}}$ slip follow the upstream $\mathrm{NO}_{\mathrm{x}}$ dynamics, the $\mathrm{NH}_{3}$ slip dynamics are slower, since its dynamics are similar to the catalyst $\mathrm{NH}_{3}$ storing capacities [29], [30]. The use of an open loop SCR model is restricted to track the $\mathrm{NH}_{3}$ loading state of the SCR. In this sense, if for any reason like sensor excursions or model inaccuracies, the SCR load $(\theta)$ is biased with regards to the actual value, the model will be inaccurate until the actual SCR load returns to a known value, which can be an empty state of the catalyst. Then, this problematic points out the need for updating this state through an observer.

Several works have been focused on designing optimal observers for the estimation of the $\mathrm{NH}_{3}$ and $\mathrm{NO}_{\mathrm{x}}$ slip by using simulations for validation purposes. Some examples can be found in [31] with a Newton observer, in [32] with a Lyapunov-based observer, or in [33], [34], [35] with an Extended Kalman Filter. Specially remarkable is the work of Zhang et al., which is focused on the observation of the operation of single-cell [36], [37] and double-cell [38], [39] 
SCR systems by designing Luenberg-like observers with SCR models based in three states, namely ammonia and NOx concentrations, and SCR coverage ratio, and by assuming pre-calibrated cross-sensitivity as a function of the temperature.

The observer presented in this work analyses sensor signals that can be found nowadays in vehicles, i.e. inlet and outlet $\mathrm{NO}_{\mathrm{x}}, \mathrm{NH}_{3}$ injection estimation, temperature, pressure and exhaust mass flow, and estimates an intermediate state that represents the SCR load to discern between $\mathrm{NH}_{3}$ and $\mathrm{NO}_{\mathrm{x}}$ slip. In contrast with previous works, here an observer with a single state (the SCR load) is modelled by analysing the emptying and filling dynamics of the SCR, and a variable update of the state from a NOx conversion model is proposed by using an EKF with variable noise. The SCR load is updated faster when no NOx is measured at the inlet of the SCR and hence all NOx measured at the outlet can be assumed ammonia slip caused by sensor cross-sensitivity.

The presented model makes use of several hypothesis in order to capture the main characteristics of the SCR but taking into account the existing limitations in real operating conditions, such as variable cross-sensitivity, or inaccurate prediction of $\mathrm{NO}_{\mathrm{x}}$ sensor and transport dynamics. Furthermore its computational burden is low and its linearization facilitates the Kalman filter state space with limited associated errors. The developed algorithm has been validated with experimental data and had shown the potential to be implemented in real time applications for control and diagnosis purposes.

\section{EXPERIMENTAL SET-UP}

Experimental tests were carried out in a dynamic engine test bench, to which a turbocharged 1.51 common-rail direct injection Euro 6 Diesel engine was coupled. The engine has an intercooled exhaust gas recirculation (EGR) valve and a variable geometry turbine (VGT), whose relevant characteristics are summarized in Table I.

TABLE I: PSA dV5 Engine main characteristics.

\begin{tabular}{ll}
\hline Stroke (S) x Bore (D) & $84.8 \times 75 \mathrm{~mm}$ \\
Number of cylinders (z) & 4 \\
Displacement & $1498 \mathrm{cc}$ \\
Compression ratio & $16: 1$ \\
Maximum torque & $300 \mathrm{Nm} @ 1750 \mathrm{rpm}$ \\
Emission standard & Euro 6 \\
\hline
\end{tabular}

The engine ATS is composed of a compacted unit with DOC, SCR and SCR filter (SCRF), where the mixing chamber for the $\mathrm{NH}_{3}$ injection is located between the DOC and the SCR. The Horiba Dyno3 engine bench was controlled with a STARS system, i.e. an automation system provided by Horiba for running a wide range of Test Programs from simple manual testing to dynamic automatic tests, to which several temperature and pressure measurements along the exhaust line were connected. An image of the engine test bench and the instrumented after-treatment system is shown in Figure 1.

A hardware-in-the-loop system was implemented in the test bench, in order to perform the real time signal separation
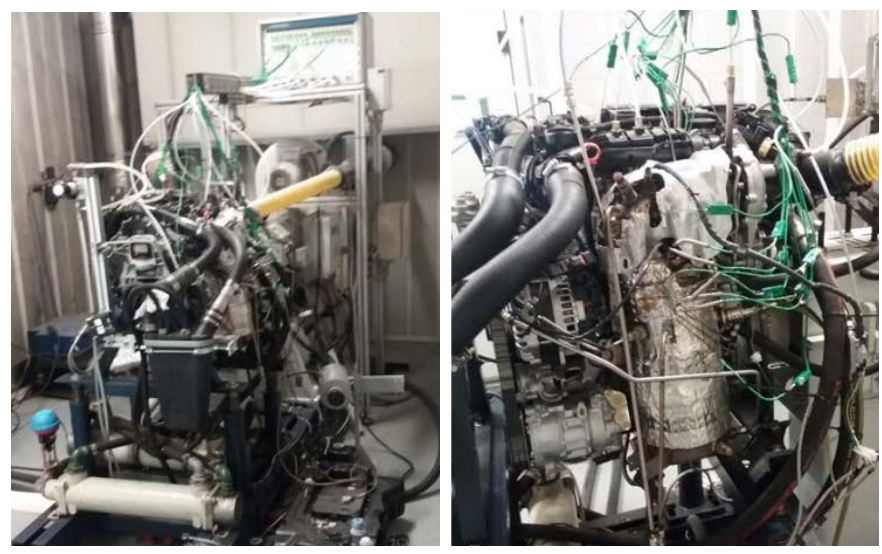

Fig. 1: Image of the engine (left) and after-treatment system (right).

strategy with a dSpace microautobox II rapid prototyping system. Then, the prototyping system was connected to an ETAS 910, which was connected to the electronic control unit (ECU) of the engine and allowed to perform bypass control. In this sense, while the NOx sensors were connected to the ECU, the $\mathrm{NH}_{3}$ sensor was connected to the prototyping system.

The necessary signals to execute the algorithm are the exhaust mass flow, the temperature and pressure of the exhaust gases, the inlet NOx signal, the outlet NOx signal and the $\mathrm{NH}_{3}$ injection flow, while the $\mathrm{NH}_{3}$ sensor was used only for calibration and to validate the strategy performance. Figure 2 shows an scheme of the engine and after-treatment layout, where the relevant systems and sensors have been highlighted.

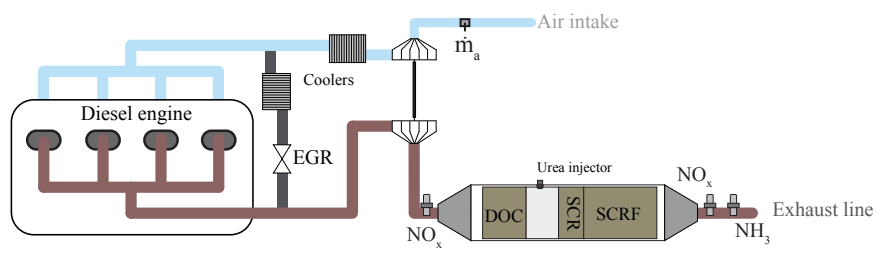

Fig. 2: Experimental test bench engine and after-treatment system layout.

Various tests were carried out in the engine with variable $\mathrm{NH}_{3}$ dosing and by varying the engine operating conditions. In this paper, only three tests will be shown to illustrate the characteristics of the developed approach: two training tests, one at low and other at high temperature, and a validation test, which consists in a World Harmonized Light-Duty Test Procedure (WLTP) cycle. Figure 3 shows the temperature (top plots), mass flow (middle plots), and inlet NOx (bottom plots) of three aforementioned tests.

\section{METHOD DESCRIPTION}

The presented methodology designs a Kalman filter that makes use of a simplified OD model, which is able to capture the main features of the SCR system but has low 


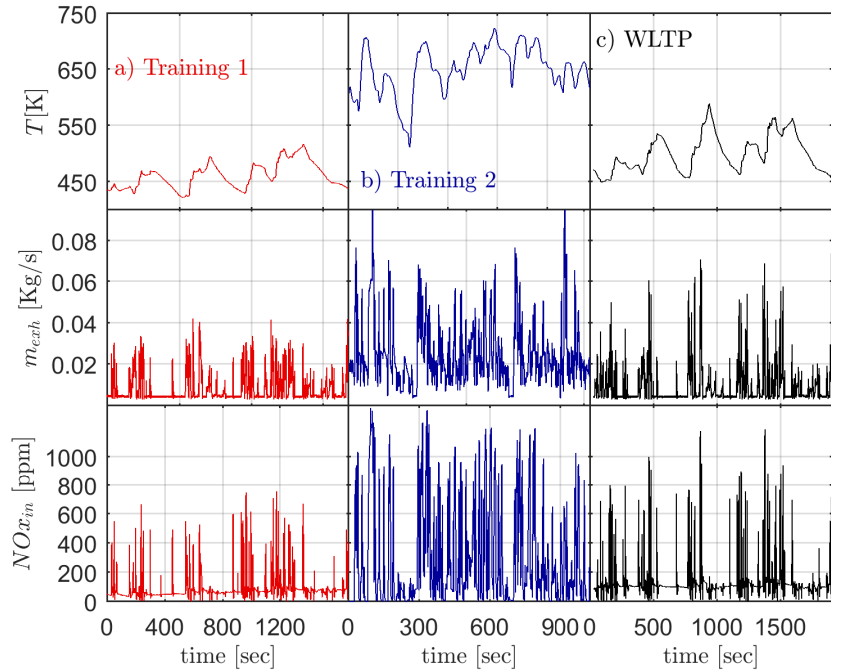

Fig. 3: Temperature (top), mass flow (middle), and inlet NOx (bottom) of three tests used to analyse the algorithm: a) training dataset at low temperature, b) training dataset at high temperature, and c) WLTP cycle.

computational burden and is suitable for being linearized.

SCR model: The SCR model used in the current approach is based on four hypothesis.

1) The cross sensitivity, that evaluates which is the influence of the $\mathrm{NH}_{3}$ slip on the outlet $\mathrm{NOx}$ measurement, can be represented by a constant value of 0.67 , such as suggested in [11]. The sensors used in the present paper have been evaluated at various operating conditions, showing a crosssensitivity close to that value.

$$
N O x_{S S}=N O x_{\text {out }}+0.67 N H 3_{\text {out }}
$$

where $N O x_{S S}$ is the outlet NOx measurement, $N O x_{\text {out }}$ the NOx slip, and $\mathrm{NH}_{\text {out }}$ the $\mathrm{NH}_{3}$ slip.

2) The mass conservation can be applied between the inlet and the outlet of the SCR to estimate its load $(\theta)$.

$$
\frac{\delta \theta}{\delta t}=\left(N H 3_{\text {in }}-\Delta N O x-N H 3_{\text {out }}\right)
$$

where $\mathrm{NH}_{3}$ in is the the $\mathrm{NH}_{3}$ absorbed by the SCR, and $\triangle N O x$ the $\mathrm{NH}_{3}$ used for NOx conversion. The model assumes that $1 \mathrm{ppm}$ of $\mathrm{NH}_{3}$ is used to convert $1 \mathrm{ppm}$ of NOx, and considers that all the $\mathrm{NH}_{3}$ injected is absorbed by including its dynamics at the desorption process. The NOx used for conversion can be also rewritten as:

$$
\Delta N O x^{k}=N O x_{i n}^{k}-N O x_{S S}^{k}+0.67 N H 3_{\text {out }}^{k}
$$

3) The NOx variations along the SCR volume $(\delta V)$ and over the time $(\delta t)$ are proportional to the existing NOx in the SCR, and the SCR load, with a proportional value which depends on the temperature, following:

$$
\frac{\delta^{2} N O x}{\delta t \delta V}=N O x \theta f_{2}^{\prime}(T)
$$

where the influence of the temperature, $f_{2}^{\prime}(T)$, use to be represented by an Arrhenius function, such as in [23]. This equation is composed from an exponential function of the SCR load and the residence time when it gets discretized, such as:

$$
N O x_{\text {out }}=N O x_{\text {in }} e^{-\theta f_{2}(T) \Delta t}
$$

where $\Delta t$ is the residence time, and $f_{2}(T)$ represents the effect of the temperature.

4) The $\mathrm{NH}_{3}$ slip is proportional to the SCR load and the mass flow, and the proportional value is function of the temperature:

$$
N H 3_{\text {out }}=m_{\text {exh }} \theta f_{1}(T)
$$

where $\theta$ is the SCR load, $f_{1}(T)$ represents the effect of the temperature, which is expected to have an Arrhenius-like shape, $m_{e x h}$ the mass flow, and $T$ the temperature of the gases.

Other SCR models such as [23] or [26] make use of a maximum SCR load to model the absorption and desorption of the SCR in order to maintain the SCR load under desired levels even in the case of a possible a model bias. In this work a simplified expression of the $\mathrm{NH}_{3}$ slip has been chosen to facilitate the linearisation and use of such model in a Kalman filter and because the SCR load will be continuously updated during the operation, avoiding a possible integration of errors in terms of bias in the SCR load.

The residence time in the SCR $(\Delta t)$ has been calculated by integrating the instantaneous speed $\left(V_{e x h}\right)$ until the length of the SCR $\left(L_{S C R}\right)$ is reached:

$$
L_{S C R}=\int_{t}^{t=t+\Delta t} V_{e x h}(t) d t
$$

where the instantaneous speed is computed by assuming an average frontal area of the SCR $\left(A_{f}=\pi D_{S C R}^{2} / 4\right)$, and by obtaining the instantaneous density $(\rho)$ from the exhaust temperature $(T)$ and pressure $\left(p_{e x h}\right)$ :

$$
V_{e x h}=\frac{m_{e x h}}{\rho A_{f}}=\frac{m_{e x h} 4 R T}{p_{e x h} \pi D_{S C R}^{2}}
$$

where $R$ is the constant of the gases $(R \approx 287 \mathrm{~J} / \mathrm{KgK})$.

An adequate identification of the residence time through $D_{S C R}$ and $L_{S C R}$ is important to study the NOx conversion, i.e. the inlet NOx signal must be delayed in order to be compared with the outlet NOx measurement. The top plot of Figure 4 shows the residence time obtained during a transient by using $D_{S C R}=11 \mathrm{~cm}$ and $L_{S C R}=1.4 \mathrm{~m}$, and the bottom plot of the Figure shows the inlet NOx raw signal $\left(N O x_{i n}^{r a w}\right)$, the inlet signal delayed $\left(N O x_{i n}\right)$ and the outlet NOx signal $\left(N O x_{\text {out }}\right)$.

The aim of the Kalman filter is the observation of an intermediate state, the SCR load, in order to distinguish the 


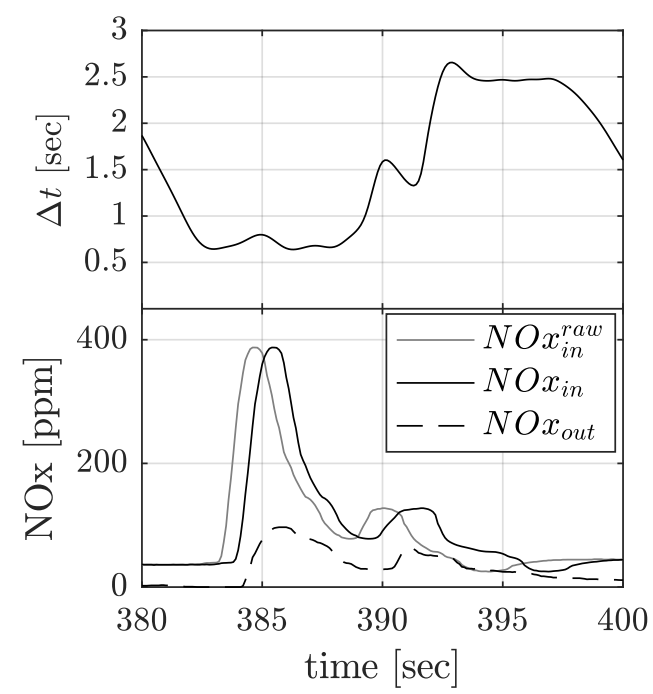

Fig. 4: Residence time and NOx signals obtained in a transient.

$\mathrm{NH}_{3}$ and the NOx slip in the outlet NOx sensor. In fact, the Kalman filter combine two sources of information, with different dynamic characteristics:

- The mass conservation: It estimates the evolution of the $\mathrm{NH}_{3}$ load by analysing the inlet and outlet measurements. When combining Equation (2), with the $\mathrm{NH}_{3}$ slip assumption, Equation (6), and the cross-sensitivity, Equation (1), it leads to:

$$
\begin{aligned}
& \theta^{k+1}=\theta^{k}+d t\left[N H 3_{i n}^{k}-N O x_{i n}^{k}+N O x_{S S}^{k}\right. \\
& \left.-1.67 \theta^{k} m_{e x h}^{k} f_{1}\left(T^{k}\right)\right]
\end{aligned}
$$

Here, all the units are used in the international system. Sensors commonly use ppm for the signal output, however, the conversion is direct when using the mass flow and the molecular weights:

$$
N O x[K g / s]=N O x[p p m] \frac{17}{29} m_{e x h}[K g / s]
$$

- A NOx conversion model: The model of NOx conversion can be used in combination of the inlet and outlet NOx measurement to determine which is the SCR load that fits the NOx conversion. From Equations (1) and (5):

$$
N O x_{S S}^{k}=N O x_{i n}^{k} e^{-\theta^{k} f_{2}\left(T^{k}\right) \Delta t^{k}}+0.67 \theta^{k} m_{e x h}^{k} f_{1}\left(T^{k}\right)
$$

It must be remarked that if the inlet NOx are negligible the NOx conversion model is not used, leading to:

$$
N O x_{S S}^{k}=0.67 \theta^{k} m_{e x h}^{k} f_{1}\left(T^{k}\right)
$$

Note that in Equation (9) the NOx conversion model is not used, but analyses the inlet and outlet measurements during the last cycles for characterizing the emptying and filling of the SCR, while Equation (11) gives an instantaneous estimation of the SCR load that would fit the NOx conversion model, but it does not use the injected $\mathrm{NH}_{3}$. On the one hand, the mass conversion might predict the dynamics of the SCR load evolution but might integrate a bias in the model ending up with an inadmissible error prediction, which would lead to significant errors in the final ammonia slip and NOx conversion efficiency estimation. On the other hand, the value given by the NOx reduction model offers a value of SCR load at each time lapse, but small errors in the model, in the signals or in the dynamics of the signals, might be amplified leading to high noise measurement.

To combine these two sources of information a Kalman filter with one state and one measurement is used, being the state the SCR load $(\theta)$, and the output the outlet NOx sensor measurement $\left(N O x_{S S}\right)$. The state representation can be defined by:

$$
\begin{aligned}
\theta^{k+1} & =f\left(\theta^{k}, u^{k}\right)+w^{k} \\
N O x_{S S}^{k} & =g\left(\theta^{k}, u^{k}\right)+v^{k}
\end{aligned}
$$

where $u$ are the inputs that define the system in a given step $k$, $w$ the associated noise to the state equation, and $v$ the noise associated to the output estimation.

Extended Kalman filter: The KF of the state vector is defined by:

$$
\begin{aligned}
\hat{\theta}^{k \mid k-1} & =f\left(\hat{\theta}^{k-1}, u^{k}\right) \\
\varepsilon^{k} & =N O x_{S S}^{k}-g\left(\hat{\theta}^{k \mid k-1}, u^{k}\right) \\
\hat{\theta}^{k} & =\hat{\theta}^{k \mid k-1}+K^{k} \varepsilon^{k}
\end{aligned}
$$

The $\mathrm{KF}$ is characterized for minimizing the expected estimation error by solving an iterative Riccati equation and updating the value of the Kalman gain $(K)$. Following:

$$
\begin{aligned}
P^{k \mid k-1}= & \left(d \theta^{k} P^{k-1} d \theta^{k}+w^{k}\right) \\
K^{k}= & P^{k \mid k-1} d N O x_{S S}^{k} \\
& \left(d N O x_{S S}^{k} P^{k \mid k-1} d N O x_{S S}^{k}+v^{k}\right)^{-1} \\
P^{k}= & \left(1-K^{k} d N O x_{S S}^{k}\right) P^{k \mid k-1}
\end{aligned}
$$

where the derivatives of the system $\left(d \theta^{k}\right.$ and $\left.d N O x_{S S}^{k}\right)$ can be obtained by linearising equations 9 and 11 with respect to $\theta$, such as:

$$
\begin{aligned}
d \theta^{k}= & 1-1.67 d t f_{1}\left(T^{k}\right) m_{\text {exh }}^{k} \\
d N O x_{S S}^{k}= & 0.67 f_{1}\left(T^{k}\right) m_{\text {exh }}^{k} \\
& -N O x_{i n}^{k} f_{2}\left(T^{k}\right) \Delta t^{k} e^{-\theta^{k} f_{2}\left(T^{k}\right) \Delta t^{k}}
\end{aligned}
$$

The associated noises $\left(w^{k}\right.$ and $v^{k}$ ), have been selected to follow the mass conservation but with a slight update when NOx is being converted and a fast update, when no NOx is converted $\left(N O_{i n} \approx 0\right)$. 


\section{CASE STUdy}

Model Calibration: The function $f_{1}$ characterizes how fast is filled and emptied the SCR at a given temperature. Figures 5 and 6 show the effect of the parameters in the first training data set (with an average temperature of $450 \mathrm{~K}$ ). The numerical values strongly depend on the operating conditions, for these concrete operating condition, i.e. this part of the first training dataset, the average values of $f_{1}$ and $f_{2}$ are 0.05 and $3.02 \mathrm{e} 4$ respectively, and the model output is $46 \mathrm{ppm}$ of average urea slip and $102 \mathrm{ppm}$ of average NOx slip.

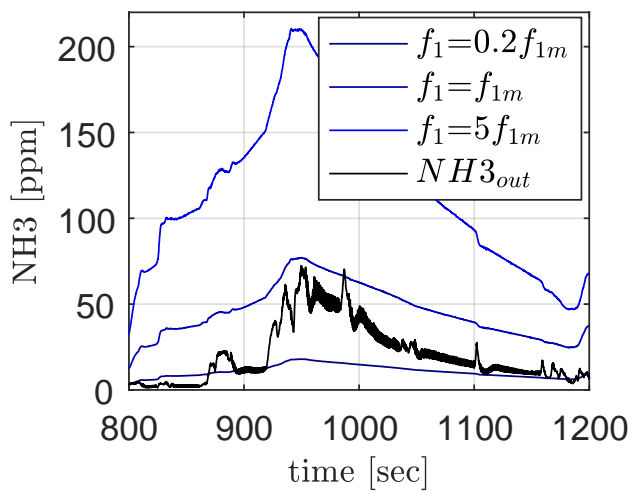

Fig. 5: Part of first training dataset where the model is used with various values of $f_{1}$.

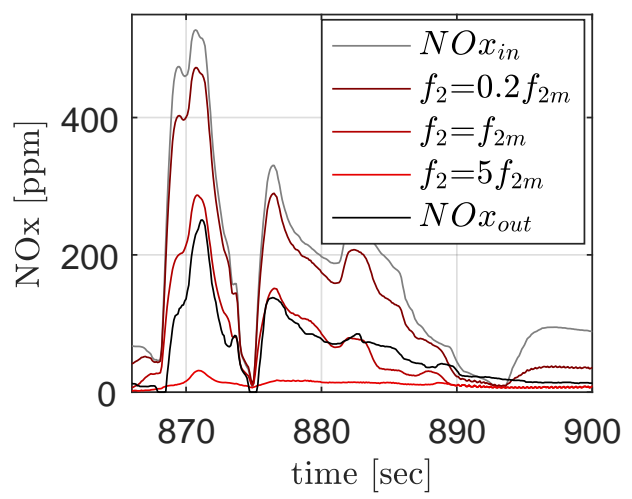

Fig. 6: Part of first training dataset where the model is used with various values of $f_{2}$.

Figure 5 shows the measured $\mathrm{NH}_{3}$ slip, the result of the model when applying the calibrated value $\left(f_{1 m}\right)$, and the effect of reducing and augmenting the parameter per five. When augmenting the value of $f_{1}$, the absorption and desorption of $\mathrm{NH}_{3}$ is accelerated, and hence the dynamics are faster. Concretely, if $f_{1}$ is multiplied by 0.2 the model would estimate an average urea slip of $10 \mathrm{ppm}$, while if it is increased 5 times, the final average urea slip would be $128 \mathrm{ppm}$.

Figure 6 shows the effect of varying the parameter $f_{2}$. When this parameter is low, such as in the first case, there is little NOx conversion and the final NOx value given by the model is close to the $N O x_{i n}$ (154 ppm in this case), but when the value is too high, such as in the third case, the conversion of NOx is amplified and hence the final value is always close to zero (31 ppm in this case).

The effect of the temperature on $f_{1}$ and $f_{2}$ is commonly simulated with Arrhenius function. However in this paper a 1D look-up-table has been preferred. A 1D look-up-table allows capturing the effect of the temperature, even with non-linear behaviour, such as in an Arrhenius function, but gives more freedom to the function and simplifies the calibration procedure for a final on-board application.

The calibration procedure proposed can be summarized in a six step procedure. For identifying the dynamics of the SCR slip, an external measurement of $\mathrm{NH}_{3}$ slip, provided by a test-bench sensor or other models, must be used:

1) The exhaust operating conditions (air mass flow and the engine-out NOx) are varied by maintaining the temperature almost constant.

2) The value of $f_{1}$ is obtained by minimizing the error in $\mathrm{NH}_{3}$ slip, optimizing:

$$
\varepsilon(N H 3)=\left|N H 3_{\text {out }}-m_{\text {exh }} \theta f_{1}\right|
$$

Note that for $f_{1}$ calibration, only the mass conservation, Equation (9), and hence the emptying and filling dynamics, are considered.

3) Once $f_{1}$ is estimated, now the experimental SCR load $\left(\theta_{\text {exp }}\right)$ is obtained from the experimental $\mathrm{NH}_{3}$ measured, such as:

$$
\theta_{\text {exp }}=\frac{N H 3_{\text {out }}}{m_{\text {exh }} f_{1}}
$$

4) Next step is based on finding $f_{2}$ by minimizing the error in the outlet NOx sensor

$$
\begin{aligned}
\varepsilon(N O x)= & \mid N O x_{S S}-\left(N O x_{i n} e^{-\theta_{\exp p} f_{2} \Delta t}\right. \\
& \left.+0.67 m_{\text {exh }} \theta_{\text {exp }} f_{1}\right) \mid
\end{aligned}
$$

5) Then the procedure is repeated at various temperatures to find the curves $f_{1}(T)$ and $f_{2}(T)$.

6) As it is difficult to obtain experimental data with significant variations of exhaust mass, outlet NOx, and SCR load at constant temperature, once the first curves are found, a second calibration procedure is proposed. In this second calibration, the full curves will be used multiplied by a constant value $\left(x_{1}\right.$ and $\left.x_{1}\right)$, to take into account the variations during the test, following:

$$
\begin{aligned}
\varepsilon(N H 3)= & \left|N H 3_{\text {out }}-m_{\text {exh }} \theta x_{1} f_{1}(T)\right| \\
\varepsilon(N O x)= & \mid N O x_{S S}-\left(N O x_{i n} e^{-\theta_{\text {exp }} x_{2} f_{2}(T) \Delta t}\right. \\
& \left.+0.67 m_{\text {exh }} \theta_{\text {exp }} x_{1} f_{1}(T)\right) \mid
\end{aligned}
$$

Figure 7 shows the result of the calibration for the SCR analysed. Note that the final function is similar to an Arrhenius function, which is in line with other modelling works.

Regarding the noise associated to the state transition and the observation model, namely $w$ and $v$, a variable noise has been used to consider different state update rates when the NOx 


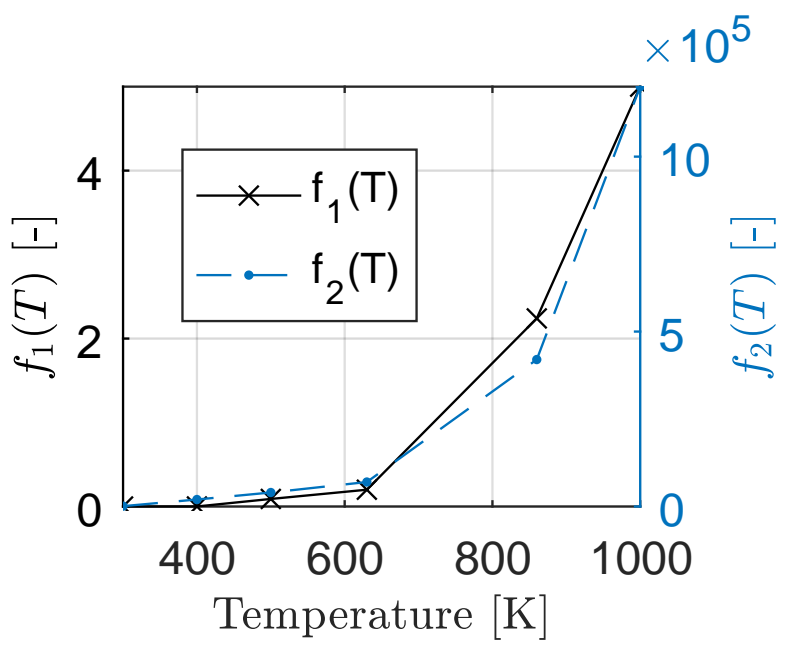

Fig. 7: Model calibration of $f_{1}(T)$ and $f_{2}(T)$.

model is not taking part in the equations.

The noise associated to the observation model $(v)$ when there is 0 NOx at the inlet of the SCR (and hence all the outlet NOx measured can be considered $\mathrm{NH}_{3}$ ) is $5 \mathrm{ppm}$, while a value of $35 \mathrm{ppm}$ has been used when the inlet NOx is above 30 ppm and hence some NOx reduction is assumed. In between, i.e. from 0 to $30 \mathrm{ppm}$, a variable noise was used to take into account the uncertainty of the NOx sensor, such as:

$$
v_{k}=\left\{\begin{array}{cl}
N O x_{i n}^{k}+5 & \text { if } N O x_{i n}^{k}<30 \\
35 & \text { if } N O x_{i n}^{k} \geq 30
\end{array}\right.
$$

A value of $1 \mathrm{mg}$ has been selected for the noise associate to the state transition model, as a trade-off between a fast adaptation and robustness. Figure 8 shows the result of the EKF when using various values for the noise associated to the state transition model. Three values of $w$ have been represented with various colour intensities, a thick red line shows the NH3 measurement and dashed line shows the output of the model without adaptation.

Note that a small value of $w(w<0.1 \mathrm{mg})$ makes the EKF rely more on the mass conservation, while a high value of $w(w>10 \mathrm{mg})$ forces a fast adaptation relying on the NOx conversion model. The effect of $v$ is somehow opposite to that of $w$, i.e. if $v$ is increased, the EKF would rely more in the mass conservation (same effect than reducing $w$ ).

The NOx sensor at the outlet is used to provide the most likely SCR load for the given measurement. Nevertheless, there are always two possibilities: either everything is urea slip detected by the cross-sensitivity, and hence the estimated SCR load is high, or the outlet NOx measured is a combination of both, urea and NOx slip, and the SCR load is lower. The objective of the EKF is to use the mass conservation and other inputs to provide the system with an adequate adaptation of the SCR load. Although a fast adaptation is sometimes desired

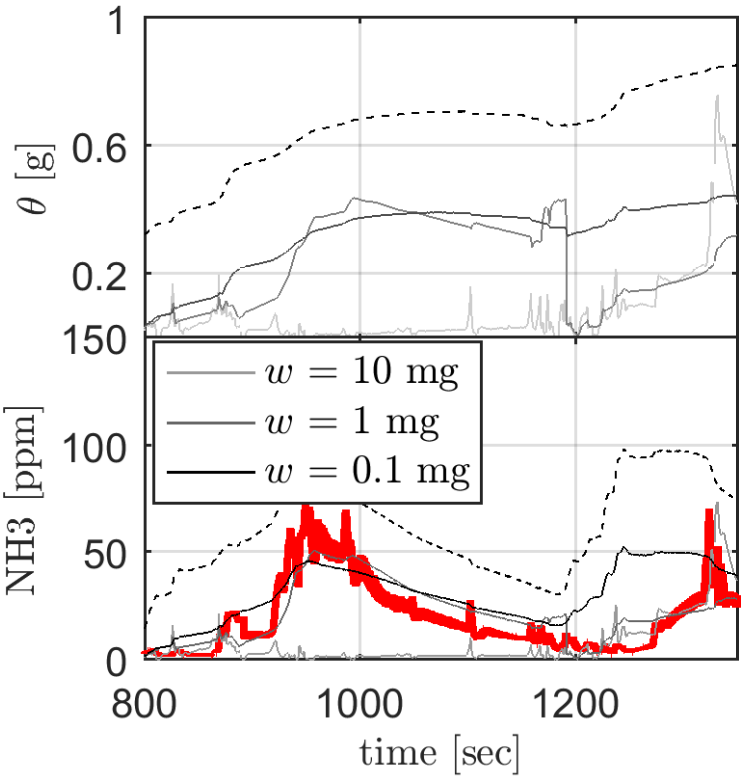

Fig. 8: EKF result of the first training dataset when using various values of $w$ : thick red line shows the NH3 measurement and dashed line shows the output of the model without adaptation.

to eliminate the bias, because of the different dynamics on the signals acquired and the model errors, the robustness of the estimation might be in danger.

One of the strengths of the EKF is its robustness to perturbations at the inputs. The use of an adaptation through the outlet NOx sensor allows the EKF to correct errors at the urea injected, at the inlet NOx or at the mass flow sensor, while using mass conservation allows the algorithm to avoid spikes caused by incorrect phasing at the outlet NOx measurement. Only an error in the cross-sensitivity error is directly propagated at the urea slip estimation but does not affect the overall performance of the algorithm.

\section{RESULTS AND DISCUSSION}

Figure 9 shows the $\mathrm{NH}_{3}$ sensor output (with a thick red line), the result of the model (with a dashed grey line), and the result of the Kalman filter (with a continuous black line) in the three tests shown in Figure 3. As it is shown, the dynamics of the measured $\mathrm{NH}_{3}$ slip is followed by the model, however a bias is produced during the tests as the model is based on the past measurements and not only the current measured signals. As consequence the NOx output of the model when using the modelled SCR load does not perfectly correlate with the NOx sensor output. The bias is corrected when using the Kalman filter with the measurement provided by the NOx sensor and a NOx conversion model to update the SCR load.

The error of the SCR model, calculated as the absolute value of the differences with the $\mathrm{NH}_{3}$ sensor, i.e. Equation (23), is $26.65,57.13$, and $66.35 \mathrm{ppm}$, for the three tests, 


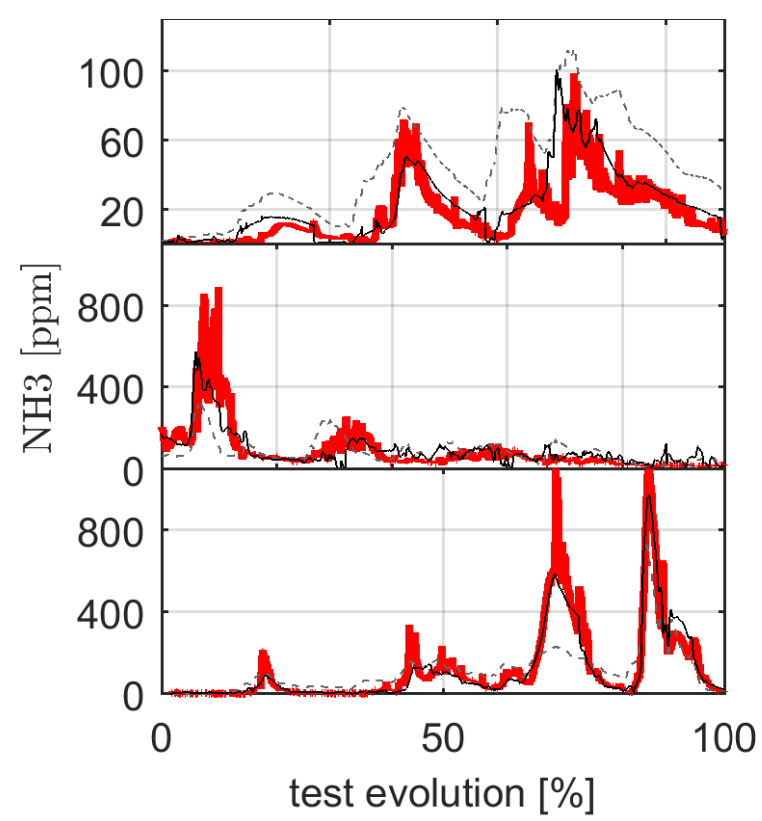

Fig. 9: $\mathrm{NH}_{3}$ slip in the three tests: training dataset at low temperature (top plot), training dataset at high temperature (medium plot), and WLTP cycle (bottom plot). A thick red line shows the NH3 measurement, a black line shows the output of the EKF and a dashed grey line shows the model result without adaptation.

which have an average $\mathrm{NH}_{3}$ measured slip of $17.71,88.24$ and $121.94 \mathrm{ppm}$. When applying the Kalman filter the error is reduced to 7.9, 41 and $32.6 \mathrm{ppm}$ at each test, that implies an error reduction of $70 \%, 40 \%$, and $50 \%$ for the three tests.

Figure 10 shows the measured NOx at the outlet (with a thick red line), the result of the model (with a dashed grey line), and the output of the Kalman filter (with a continuous black line) in a given range. The modelled NOx seems to correlate with the experimental results, however predicted NOx are underestimated or overestimated because of the bias at the SCR load. The Kalman filter follows the NOx measurement by using the error between the model and the outlet NOx sensor to correct a possible bias that might be integrated at past cycles.

\section{CONCLUSIONS}

$\mathrm{NH}_{3}$ injection in current SCR systems is based in a control scenario based on the inlet and outlet NOx sensor measurements. However, in order to use these sensors for an adequate $\mathrm{NH}_{3}$ injection strategy, an estimation of the NOx and the $\mathrm{NH}_{3}$ slip, must be provided. Current SCR models determine the $\mathrm{NOx}$ and $\mathrm{NH}_{3}$ slip based on the SCR load and predict the SCR load by using the mass conservation at the inlet and oultet of the SCR to analyse the accumulation of $\mathrm{NH}_{3}$. Nevertheless, these models use to exhibit significant errors when the initial SCR load is not known, or when model or sensor bias are integrated.

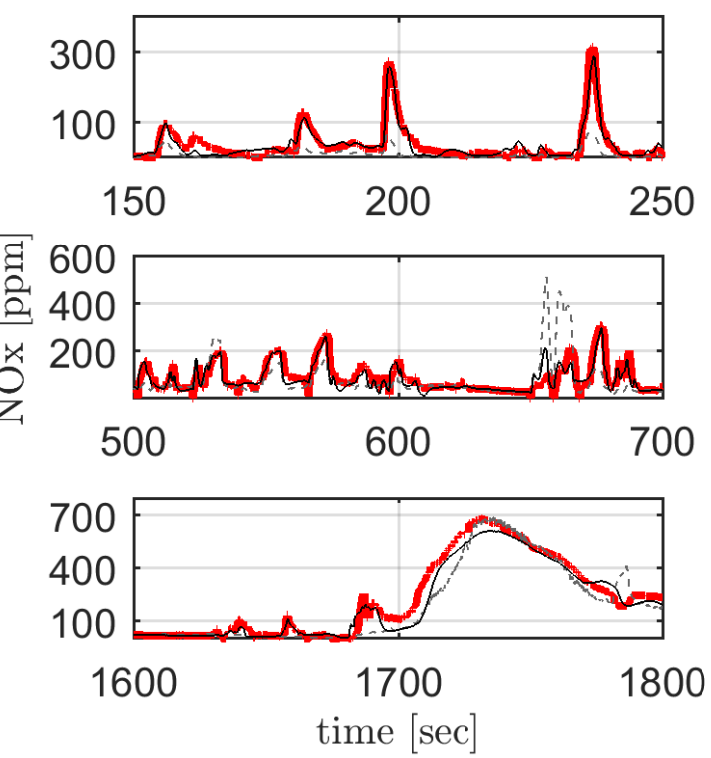

Fig. 10: NOx sensor reading in the three tests: training dataset at low temperature (top plot), training dataset at high temperature (medium plot), and WLTP cycle (bottom plot). A thick red line shows the NH3 measurement, a black line shows the output of the EKF and a dashed grey line shows the model result without adaptation.

The present paper proposes a simplified model oriented to control applications which provides a measurement of the $\mathrm{NH}_{3}$ slip based on an intermediate state which represents the SCR load. The approach makes use of two sources of information to predict the SCR load: the mass conservation to determine the evolution of the SCR load and a model of the NOx conversion efficiency to analyse which is the most likely value of SCR load at each time lapse.

A Kalman filter is used to combine both measurements by modelling the dynamics of the SCR load with the mass conservation principle and by updating the current model in two levels: with a slow update when NOx are converted, and consequently a significant error can be expected from the NOx conversion, and a fast update when no NOx are converted, and hence all the NOx measured at the outlet NOx sensors are mainly $\mathrm{NH}_{3}$ slip.

An external $\mathrm{NH}_{3}$ measurement was used to validate the proposed methodology with experimental data. Using a Kalman filter implies an error reduction of $70 \%, 40 \%$, and $50 \%$ for the three tests shown, when comparing with the results of the model. The presented approach has the potential of predicting the $\mathrm{NH}_{3}$ slip, not only qualitatively, but also to quantify it. Future works will be focused on the possibility of an online adaptation of SCR models to consider ageing factor or different exhaust lines, and the use of such measurement for SCR control purposes. 


\section{ACKNOWLEDGEMENTS}

The authors acknowledge the support of Spanish Ministerio de Economía, Inudstria y Competitividad through the project TRA2016-78717-R.

\section{REFERENCES}

[1] F. Posada and J. German, "Review of LDV OBD requirements under the European, Korean and Californian emissions programs," The international council on clean transportation, 2016.

[2] T. Johnson and A. Joshi, "Review of vehicle engine efficiency and emissions," in WCX 17: SAE World Congress Experience 2017-01-0907. SAE International, mar 2017.

[3] Z. Skaf, T. Aliyev, L. Shead, and T. Steffen, "The state of the art in selective catalytic reduction control," in SAE 2014 World Congress \& Exhibition 2014-01-1533. SAE International, 2014.

[4] J. Riegel, H. Neumann, and H.-M. Wiedenmann, "Exhaust gas sensors for automotive emission control," Solid State Ionics, vol. 152, pp. 783-800, 2002.

[5] Y.-Y. Wang, Y. Sun, C.-F. Chang, and Y. Hu, "Model-based fault detection and fault-tolerant control of scr urea injection systems," IEEE Transactions on Vehicular Technology, vol. 65, no. 6, pp. 4645-4654, 2016.

[6] R. Chen and X. Wang, "Model-based fault diagnosis of selective catalytic reduction systems for diesel engines," SAE Int. J. Passeng. Cars - Electron. Electr. Syst. 2014-01-0280, vol. 7, pp. 449-453, 042014.

[7] D. Upadhyay and M. Van Nieuwstadt, "Model based analysis and control design of a urea-SCR deNOx aftertreatment system," Journal of dynamic systems, measurement, and control, vol. 128, no. 3, pp. 737-741, 2006

[8] M. Van Nieuwstadt and D. Upadhyay, "Diagnosis of a urea scr catalytic system," Patent, 9, 2005, uS Patent 6.925.796.

[9] F. Willems, R. Cloudt, E. van den Eijnden, M. van Genderen, R. Verbeek, B. de Jager, W. Boomsma, and I. van den Heuvel, "Is closed-loop SCR control required to meet future emission targets?" in SAE Technical Paper Series 2007-01-1574. SAE International, apr 2007.

[10] A. Bonfils, Y. Creff, O. Lepreux, and N. Petit, "Closed-loop control of a scr system using a NOx sensor cross-sensitive to NH3," Journal of Process Control, vol. 24, no. 2, pp. 368 - 378, 2014.

[11] A. Frobert, S. Raux, Y. Creff, and E. Jeudy, "About cross-sensitivities of NOx sensors in scr operation," in SAE 2013 World Congress \& Exhibition 2013-01-1512. SAE International, apr 2013.

[12] D. Y. Wang, S. Yao, M. Shost, J.-H. Yoo, D. Cabush, D. Racine, R. Cloudt, and F. Willems, "Ammonia sensor for closed-loop SCR control," $S A E$ International Journal of Passenger Cars - Electronic and Electrical Systems 2008-01-0919, vol. 1, pp. 323-333, apr 2008.

[13] M. Shost, J. Noetzel, M.-C. Wu, T. Sugiarto, T. Bordewyk, G. Fulks, and G. B. Fisher, "Monitoring, feedback and control of urea SCR dosing systems for NOx reduction: Utilizing an embedded model and ammonia sensing," in SAE Technical Paper Series 2008-01-1325. SAE International, 2008.

[14] D. Yu Wang, S. Yao, D. Cabush, and D. Racine, "Ammonia sensor for SCR NOx reduction,” DELPHI, Tech. Rep., 2007.

[15] D. Blanco-Rodriguez, G. Vagnoni, and B. Holderbaum, "EU6 C-Segment Diesel vehicles, a challenging segment to meet RDE and WLTP requirements," IFAC-PapersOnLine, vol. 49, no. 11, pp. 649 - 656 2016, 8th IFAC Symposium on Advances in Automotive Control AAC 2016.

[16] P. Tourlonias and G. Koltsakis, "Model-based comparative study of Euro 6 diesel aftertreatment concepts, focusing on fuel consumption," International Journal of Engine Research, vol. 12, no. 3, pp. 238-251, 2011.

[17] R. Cloudt, J. Saenen, E. v. d. Eijnden, and C. Rojer, "Virtual exhaust line for model-based diesel aftertreatment development," in SAE 2010 World Congress \& Exhibition 2010-01-0888. SAE International, apr 2010.

[18] M. Devarakonda, G. Parker, J. H. Johnson, and V. Strots, "Model-based control system design in a urea-scr aftertreatment system based on nh3 sensor feedback," International Journal of Automotive Technology, vol. 10, no. 6, p. 653, Dec 2009.

[19] G. Cavataio, J. Girard, J. E. Patterson, C. Montreuil, Y. Cheng, and C. K Lambert, "Laboratory testing of urea-SCR formulations to meet Tier 2 bin 5 emissions," in SAE Technical Paper Series 2007-01-1575. SAE International, 2007.
[20] C. Guardiola, B. Pla, J. Mora, and D. Lefebvre, "Control oriented model for diesel oxidation catalyst diagnosis," IFAC-PapersOnLine, vol. 48, no. 15 , pp. $427-433,2015$.

[21] G. Hommen, F. Kupper, and X. Seykens, "Robust, model-based urea dosing control for SCR aftertreatment systems using a cross-sensitive tailpipe nox sensor," in SAE Technical Paper Series 2017-01-0938. SAE International, mar 2017.

[22] F. Birkhold, U. Meingast, P. Wassermann, and O. Deutschmann, "Modeling and simulation of the injection of urea-water-solution for automotive SCR DeNOx-systems," Applied Catalysis B: Environmental, vol. 70, no. 1 , pp. $119-127,2007$

[23] A. Matsumoto, K. Furui, M. Ogiso, and T. Kidokoro, "Model-based OBD logic utilizing adsorption and desorption model of NH3 in SCR catalyst," in SAE Technical Paper 2016-01-0960. SAE International, 042016.

[24] M. Colombo, I. Nova, and E. Tronconi, "Detailed kinetic modeling of the nh3-no/no2 scr reactions over a commercial cu-zeolite catalyst for diesel exhausts after treatment," Catalysis Today, vol. 197, no. 1, pp. $243-255,2012$

[25] F. Willems and R. Cloudt, "Experimental demonstration of a new modelbased scr control strategy for cleaner heavy-duty diesel engines," IEEE Transactions on Control Systems Technology, vol. 19, no. 5, pp. 13051313, 2011.

[26] D. Upadhyay and M. Van Nieuwstadt, "Modeling of urea SCR catalyst with automotive applications," 2002.

[27] I. Nova, L. Lietti, and E. Tronconi, "Transient response method applied to the kinetic analysis of the deNO x-SCR reaction," Chemical Engineering Science, vol. 56, no. 4, pp. 1229-1237, 2001.

[28] X. Song, J. D. Naber, and J. H. Johnson, "A study of the effects of NH3 maldistribution on a urea-selective catalytic reduction system," International Journal of Engine Research, vol. 16, no. 2, pp. 213-222, 2015.

[29] J. Figura, J. Pekar, P. Krejza, D. Mracek, D. von Wissel, and T. Zhang, "NO2/NOx ratio and $\mathrm{NH} 3$ storage estimation of automotive SCR multi-brick systems," in SAE Technical Paper 2017-01-0972. SAE International, 2017.

[30] T. Feng and L. Lue, "The characteristics of ammonia storage and the development of model-based control for diesel engine urea-scr system," Journal of Industrial and Engineering Chemistry, vol. 28, pp. 97 - 109, 2015.

[31] Q. Lin and P. Chen, "An NOx sensor-based direct algebraic approachnewton observer for urea selective catalytic reduction system state estimations," Journal of Dynamic Systems, Measurement and Control, Transactions of the ASME, vol. 140, no. 11, 2018.

[32] Y. Ma and J. Wang, "Observer-based estimation of aging condition for selective catalytic reduction systems in vehicle applications," Journal of Dynamic Systems, Measurement and Control, Transactions of the ASME, vol. 139, no. 2, 2017.

[33] M. F. Hsieh and J. Wang, "An extended kalman filter for NOx sensor ammonia cross-sensitivity elimination in selective catalytic reduction applications," in American Control Conference (ACC), 2010. IEEE, 2010, pp. 3033-3038.

[34] B. Jiang, Y. Hu, S. Wang, Y. Qiu, and H. Chen, "A state observer design based on EKF for diesel engine urea-SCR system," in Proceedings of the World Congress on Intelligent Control and Automation (WCICA), vol. 2016-September, 2016, pp. 3324-3329.

[35] K. Jiang, H. Zhang, and J. Lin, "NH3 coverage ratio estimation of dieselengine SCr systems by a dual time-scale extended kalman filter," IEEE Transactions on Vehicular Technology, vol. 67, no. 4, pp. 3625-3629, 2018.

[36] H. Zhang and J. Wang, "Adaptive sliding-mode observer design for a selective catalytic reduction system of ground-vehicle diesel engines," IEEE/ASME Transactions on Mechatronics, vol. 21, no. 4, pp. 2027-2038, 2016.

[37] H. Zhang, J. Wang, and Y. . Wang, "Nonlinear observer design of diesel engine selective catalytic reduction systems with nox sensor measurements," IEEE/ASME Transactions on Mechatronics, vol. 20, no. 4, pp. 1585-1594, 2015.

[38] H. Zhang, P. Chen, J. Wang, and Y. . Wang, "Integrated study of inlandvessel diesel engine two-cell scr systems with dynamic references," IEEE/ASME Transactions on Mechatronics, vol. 22, no. 3, pp. 1195-1206, 2017.

[39] H. Zhang, J. Wang, and Y. . Wang, "Sensor reduction in diesel engine twocell selective catalytic reduction (scr) systems for automotive applications," IEEE/ASME Transactions on Mechatronics, vol. 20, no. 5, pp. 2222-2233, 2015. 